\title{
Comunicação, educação e mídia. Por um ensino motivador e alegre Estudo de caso da EE Godofredo Furtado'
}

Ana Regina Gouvêa

Especialista em Gestão de Processos Comunicacionais pela Escola de Comunicações e Artes da Universidade de São Paulo e professora de matemática da rede pública.

E-mail: anacantgoliveira@yahoo.com.br

O presente relato insere-se na área emergente do campo da comunicação conhecida por educomunicação, ou seja, a inter-relação entre as ciência da comunicação e a teoria e prática da educação. Uma área que visa a estender os conhecimentos dos meios de comunicação de massa - linguagem, tecnologia e mediações - às questões com as quais se depara o profissional da educação - aprendizagem, conhecimento e consciência crítica. No encontro desses campos teóricos e dessas práticas sociais, surgem estudos que visam a conhecer e discutir a cultura midiática de alunos e professores, ou seja, seus hábitos de consumo midiático, de maneira a apreender a realidade que o cerca a partir de informações que lhe chegam pelos meios de comunicação de massa - o rádio, o cinema, a televisão e a internet. Esses estudos visam a conhecer, discutir e compreender o imaginário de nossos alunos de forma a, a partir dele, estabelecer uma relação pedagógica mais viva, efetiva e construtiva.

Entende-se que o uso dos meios de comunicação na educação podem tornála mais inclusiva, ampliando as possibilidades de comunicação e expressão dos alunos, especialmente num país como o nosso, com alta taxa de analfabetismo funcional, como apontam as avaliações. Não se trata de abandonar o ideal de alfabetização plena de todos os alunos, mas de pressupor que, a partir de linguagens sobre as quais têm maior domínio, os estudantes poderão apresentar menor dificuldade e menos resistência ao aprendizado. Não só da linguagem escrita, mas também da oral. Da mesma forma, partindo do conhecimento que transita pelos meios de comunicação torna-se mais fácil chegar ao conhecimento formal e até ao apuro do gosto e à formação de um público mais exigente em relação ao que vê, ouve ou assiste.

Com base nesses pressupostos, passo a relatar a pesquisa que desenvolvi na EE Godofredo Furtado, como professora, tendo como objetivo avaliar as expe-

1. Trabalho apresentado ao Departamento de Comunicações e Artes da Escola de Comunicações e Artes da Universidade de São Paulo, como requisito parcial para obtenção do título de especialista em nível de pós-graduação em Gestão de Processos Comunicacionais. Orientadora: Profa. Dra. Maria Cristina Castilho Costa. São Paulo, 2002. 
riências que vinha realizando, de maneira quase informal e espontânea, com o rádio nas atividades escolares em práticas anteriores (no ensino fundamental) e desenvolver um projeto consistente de comunicação, inserindo outros meios de comunicação de massa no cotidiano da aprendizagem.

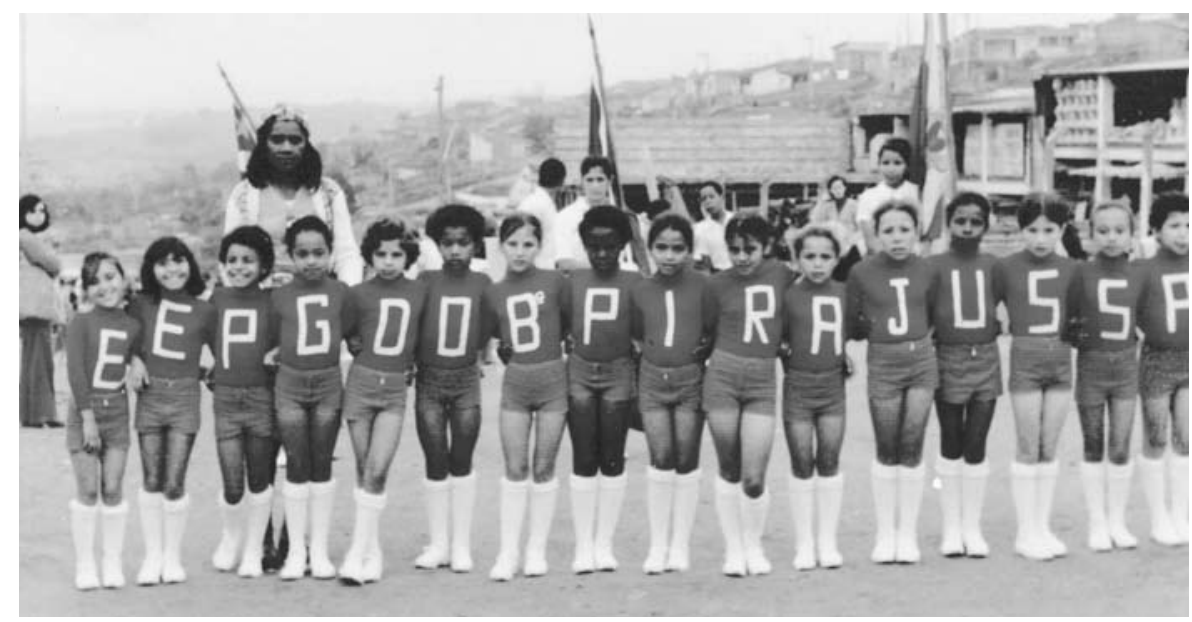

Experiência e sensibilidade motivaram a investigação sobre o efeito dos meios de comunicação de massa no cotidiano escolar. A Profa. Ana Gouvêa com alunas, no início da carreira.

Diversas haviam sido minhas iniciativas de tornar o convívio em sala de aula e o conhecimento da Matemática - disciplina da qual sou professora - mais amenos e prazerosos. O rádio foi o meio pelo qual pude criar uma ligação mais próxima com meus alunos e estabelecer um pacto que facilitou nosso relacionamento. Passei a incorporar a música, escolhida em comum acordo com os alunos, nos exercícios escolares. Essa iniciativa, vista com estranheza pelos professores que nos viam e ouviam do corredor, mostrou-se um recurso produtivo - os alunos se aproximavam mais de mim e da matéria e passaram a encarar a difícil matemática com mais facilidade e sucesso, diminuindo o grau de incerteza no aprendizado da disciplina.

Para compreender de forma científica a relação entre comunicação e educação, resolvi ingressar em um curso de pós-graduação lato sensu - Gestão de Processos Comunicacionais [atualmente, Gestão da Comunicação] da Escola de Comunicações e Artes da Universidade de São Paulo, para tornar-me especialista nessa área. $\mathrm{O}$ texto que se segue obedece aos princípios metodológicos aprendidos no curso para o qual desenvolvi um projeto de intervenção, com base nos princípios de educomunicação para obtenção do título de gestora da comunicação.

\section{O OBJETO DE PESQUISA}

A escola estadual Godofredo Furtado foi criada por decreto, em 15.1.1925, e o ato de instalação foi em 25.1.1925, pela Lei 357, de 23.7.1974. Está situada na rua João Moura, 727, Jardim América, São Paulo. A escola oferece o primeiro e o segundo graus; o ensino supletivo funcionou até 1996. 
Como em outras escolas, um dos problemas mais agudos é uma grande insatisfação observada entre os alunos de maneira geral, o que traz como conseqüência inquietação, comportamentos inadequados, ausências nas aulas, evasão escolar etc. Outro problema preocupante é o desemprego que atinge em grande parte os pais, os irmãos e até os próprios alunos do curso noturno. Embora não diretamente ligado à vida escolar, isso afeta o ânimo dos alunos e sua atitude perante a educação e suas expectativas em relação a ela.

Nesse cenário, observa-se entre os professores, ainda que tímida, uma predisposição ao trabalho interdisciplinar, coletivo ou grupal, com a introdução de novas estratégias de aprendizagem. E, apesar da resistência de alguns, na elaboração do projeto anual houve maior participação dos professores, com novas perspectivas de trabalho, tendo sido apontada, entre outras estratégias, a incorporação dos meios de comunicação de massa e das linguagens midiáticas no processo educativo.

Outras sugestões apontavam para reformas do espaço físico e modificações dos recursos pedagógicos, as quais vinham sendo contempladas em projetos que, desde 2001, eram desenvolvidos em parcerias com ONGs. Uma dessas iniciativas, o Projeto Tarsila do Amaral, possibilitou que os muros da escola fossem renovados com pinturas realizadas pelos alunos.

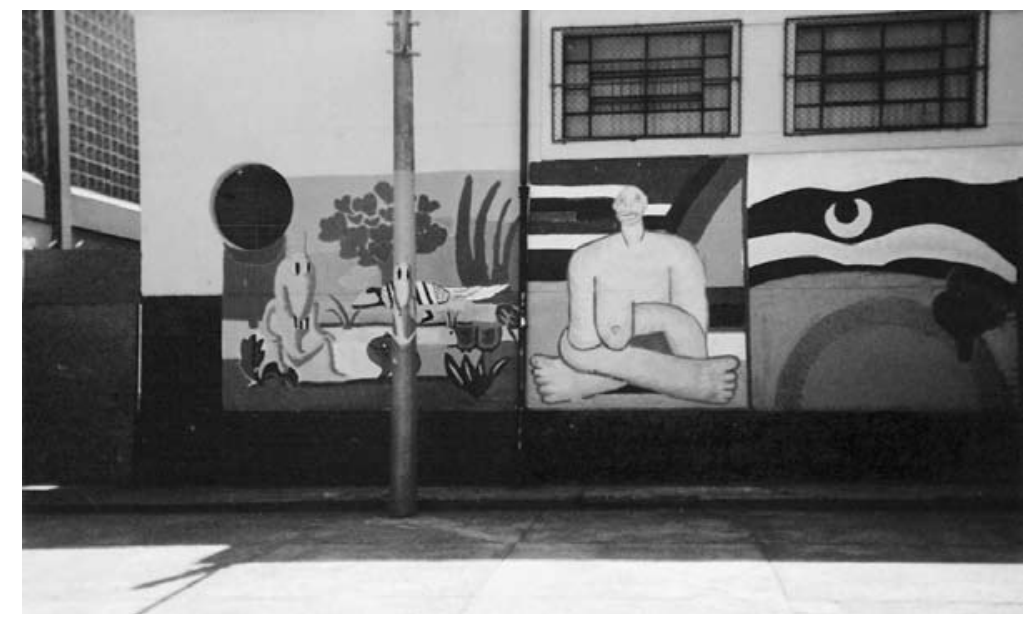

Projeto Tarsila do Amaral: pinturas realizadas pelos alunos da EE Godofredo Furtado.

\section{PROPOSTA PEDAGÓGICA DA EE GODOFREDO FURTADO}

As reuniões de avaliação pedagógica detectaram os seguintes problemas como os mais urgentes, exigindo ação imediata dos professores:

1. Necessidade de construir um trabalho coletivo e participativo de forma democrática.

2. Articulação entre projetos de vida e contexto escolar.

3. Superação da defasagem de aprendizagem detectada pelo resultado do SARESP, de janeiro de 2002, acusando que apenas $70 \%$ de alunos do ensino fundamental dominam as cinco habilidades de leitura e interpretação de textos. 
comunicação \& educação • Ano XI • Número 1 • jan/abr 2006

4. Comportamento inadequado dos alunos, especialmente em algumas séries, prejudicando a aprendizagem e o vínculo entre alunos e desses com a escola.

Foi diante dessas questões que, como aluna do curso de Gestão de Processos Comunicacionais, decidi-me por investigar o consumo midiático dos alunos, com o intuito de introduzir atividades que renovassem a prática educativa, estimulando o interesse, a motivação, o entendimento dos alunos, prejudicados em decorrência de premissas pedagógicas conservadoras e de um contexto social desestimulante para a educação formal. Descobrir o que os alunos lêem, ouvem ou assistem apresentava-se como uma estratégia adequada para compreender seus anseios, sonhos, expectativas, interesses e hábitos, mobilizando-os a um trabalho mais intenso e fecundo.

\section{METODOLOGIA}

Na época de realização da presente pesquisa, a escola possuía 1.151 alunos, sendo 391 do ensino fundamental e 917 do ensino médio. Eram 45 professores e 12 funcionários. Dada a quantidade de alunos desse universo, decidimos realizar a pesquisa com uma amostra. Escolhemos os alunos da 8a série do ensino fundamental, período da manhã, e os terceiros anos do ensino médio, que funcionam nos períodos diurno e noturno.

Essa escolha deveu-se ao fato de serem séries finais e, também, pela faixa etária compreendida, pois abrange alunos que já têm hábitos de consumo midiático bastante arraigados. Outro fator é que esse grupo de alunos era o que apresentava maior incidência de atitudes problemáticas no que diz respeito às questões já abordadas - desatenção, evasão etc. A pesquisa envolveu, assim, 26 alunos da 8aㅗ série, cuja faixa etária é de 13 a 15 anos, e 24 alunos dos terceiros anos, idades entre 18 e 36 , perfazendo um total de 50 participantes.

\section{INSTRUMENTO}

O instrumento utilizado nessa amostra foi um questionário especialmente elaborado para detectar o consumo midiático dos alunos e suas opiniões acerca das experiências que, de forma ainda experimental e informal (não planejada), eu havia realizado ao introduzir o rádio nas atividades didáticas. A aplicação dos questionários aos alunos ocorreu de 10 a 23 de outubro de 2005, durante os períodos regulares de aula, quando eu poderia contar com a atenção dos alunos e o controle da maneira como respondiam às perguntas. Os alunos mostraram-se interessados nessa atividade e não encontrei nenhum problema na sua realização. 


\section{PESQUISA DE CAMPO \\ MODELO DO QUESTIONÁRIO}

Nome

Idade

Sexo

Profissão

Série

Este é um questionário para levantar o consumo dos meios de comunicação pelos alunos, com o objetivo de integrá-los às nossas atividades didáticas. Agradecemos a sua participação.

1. Dos meios de comunicação abaixo, quais e como você os utiliza?

\begin{tabular}{|c|c|c|c|c|c|c|c|c|c|}
\hline & Não & Sim & Diário & $\begin{array}{c}\text { Duas a três vezes } \\
\text { por semana }\end{array}$ & Semanal & Quinzenal & Mensal & Raramente & Quantas horas \\
\hline Jornal & & & & & & & & & \\
\hline Revista & & & & & & & & & \\
\hline Rádio & & & & & & & & & \\
\hline Televisão & & & & & & & & & \\
\hline $\begin{array}{l}\text { Gravador } \\
\text { de som }\end{array}$ & & & & & & & & & \\
\hline Walkman & & & & & & & & & \\
\hline Videocassete & & & & & & & & & \\
\hline DVD & & & & & & & & & \\
\hline Computador & & & & & & & & & \\
\hline Internet & & & & & & & & & \\
\hline
\end{tabular}

2. Qual é o programa de rádio que você mais gosta?
Musicais
[ ]
Reportagens
Entrevista
[ ]
Esporte

3. Na televisão você assiste mais a:

$\begin{array}{llll}\text { Telenovela } & {[\text { ] }} & \text { Infantil } & {[\text { ] }} \\ \text { Jornal } & {[\text { ] }} & \text { Programa de entrevista } & {[\text { ] }} \\ \text { Humor } & {[\text { ] }} & \text { Esporte } & {[\text { ] }} \\ \text { Programa de auditório } & {[\text { ] }} & \text { Documentário } & {[\text { [ ] }} \\ \text { Desenho/animação } & {[\text { ] }} & \text { Filme } & {[\text { ] }}\end{array}$

4. A que tipo de filme você costuma assistir?

$\begin{array}{lll}\text { Ação } & {[\text { ] }} & \text { Guerra } \\ \text { Romance } & {[\text { ] }} & \text { Drama } \\ \text { Policial } & {[\text { ] }} & \text { Musical }\end{array}$

5. Qual é o estilo musical de sua preferência? 
comunicação \& educação • Ano XI • Número 1 • jan/abr 2006

6. Você possui computador?
Sim [ ]
Não [ ]

7. Sabe usar?
$\operatorname{Sim}[]$
Não [ ]

8. Para qual finalidade você usa?

9. Quando acessa a internet, o que você procura?

10. Qual é o jornal que você costuma ler?

11. Qual a seção?

12. Qual(is) a(s) revista(s) que você costuma ler?

13. Você gostaria que esses meios citados fossem usados na escola?
$\operatorname{Sim}[$ ]
Não [ ]

14. Como você acha que isso seria possível?

15. O que você pensou quando assistiu à aula de Matemática em que, pela primeira vez, a professora ligou o rádio?

16. Em que série estava?

17. Explique a diferença da aula sem rádio e com rádio?

18. Na sua opinião, como se comportam os alunos quando tem rádio na sala de aula? E sem o rádio?

A etapa seguinte à aplicação do questionário foi a análise de dados com a tabulação das informações obtidas e a criação de tabelas para análise. Para mim, como professora de Matemática, essa parte foi a mais fácil. 
Tabela 1

Quais os meios que você utiliza?

\begin{tabular}{|c|c|c|c|c|c|c|c|c|c|c|c|c|c|}
\hline \multirow{27}{*}{ 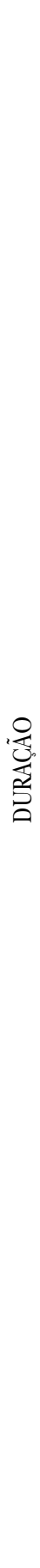 } & \multirow{3}{*}{ 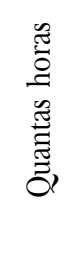 } & 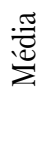 & - & 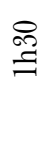 & $\begin{array}{l}\text { ๑ } \\
\stackrel{7}{7}\end{array}$ & $\begin{array}{l}\text { ๑ి } \\
\text { fै }\end{array}$ & ' & $\begin{array}{l}\text { वे } \\
\text { a }\end{array}$ & लี & $\stackrel{\text { I }}{=}$ & ली & aี & $\stackrel{\text { 号 }}{=}$ \\
\hline & & 의 & o & ov & + & + & ' & 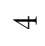 & 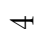 & 一 & $\forall$ & + & $\mathscr{2}$ \\
\hline & & 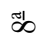 & ' & 一 & 20 & ס 2 & ' & 一 & ov & ov & $\sigma$ & ' & $\infty$ \\
\hline & \multirow{3}{*}{ 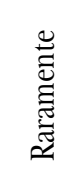 } & 点 & $\infty$ & $\Xi$ & or & ' & ov & 0 & $\infty$ & - & or & os & 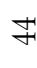 \\
\hline & & of & תג & $\nabla$ & or & ' & - & ' & $\infty$ & - & ov & - & $\sigma$ \\
\hline & & 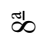 & on & 1 & ' & ' & - & 0 & 20 & ' & 一 & $\sigma$ & ๙2 \\
\hline & \multirow{3}{*}{$\begin{array}{l}\bar{F} \\
\overrightarrow{0} \\
\vec{E}\end{array}$} & 吾 & ' & + & - & ' & - & ' & or & ov & - & ' & $=$ \\
\hline & & in & ' & + & - & ' & ' & ' & ov & I & - & ' & $\infty$ \\
\hline & & $\infty$ & ' & ' & ' & ' & - & ' & ' & $\sigma$ & ' & ' & or \\
\hline & \multirow{3}{*}{ 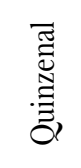 } & 坖 & or & ' & ' & ' & ' & ' & ov & ov & ' & - & 20 \\
\hline & & in & or & ' & ' & ' & ' & ' & - & ' & ' & ' & - \\
\hline & & $\infty$ & ' & ' & ' & ' & ' & ' & - & or & ' & - & 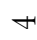 \\
\hline & \multirow{3}{*}{ 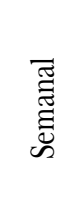 } & 吾 & 0 & $n$ & $r$ & ס 20 & ov & ' & 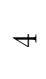 & $\infty$ & 20 & or & Fั \\
\hline & & is & 0 & $\infty$ & 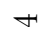 & or & $\neg$ & ' & $\infty$ & $\sigma$ & $\sigma$ & on & $\sim$ \\
\hline & & $\infty$ & ' & 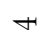 & $\infty$ & $\infty$ & - & ' & - & - & $\infty$ & ' & $\underline{0}$ \\
\hline & \multirow{3}{*}{ 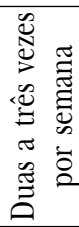 } & 퓽 & $\infty$ & 으 & $\infty$ & 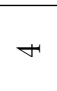 & ov & or & or & - & $r$ & $\infty$ & F \\
\hline & & on & on & $\infty$ & or & + & or & - & or & ' & - & - & নิ \\
\hline & & $\infty$ & 10 & 1 & ' & ' & ' & 一 & ' & - & 0 & $r$ & $\hat{a}$ \\
\hline & \multirow{3}{*}{ 凉 } & 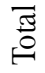 & $n$ & 20 & 天े & के & 0 & 20 & or & - & $\sigma$ & $r$ & $\stackrel{\mathscr{V}}{\varrho}$ \\
\hline & & on & or & $\sigma$ & 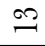 & $\stackrel{2}{\longrightarrow}$ & ov & $\infty$ & 一 & 一 & 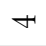 & + & $\mathscr{f}$ \\
\hline & & $\infty$ & + & $\infty$ & $\exists$ & $\approx$ & $\sigma$ & $\sigma$ & - & ' & 10 & $\infty$ & है \\
\hline & \multirow{3}{*}{ 洁 } & 吾 & 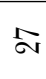 & 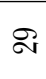 & $\mathscr{q}$ & Fै & $\exists$ & 0 & ح) & 으 & $\stackrel{\vec{N}}{ }$ & $\infty$ & $\stackrel{20}{a}$ \\
\hline & & is & 0 & $\infty$ & $\stackrel{\infty}{\infty}$ & $\Omega$ & on & $\sigma$ & 20 & 10 & $\infty$ & $r$ & $\stackrel{\infty}{=}$ \\
\hline & & 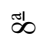 & $\equiv$ & $=$ & à & $\mathscr{2}$ & $\infty$ & $N$ & $\Xi$ & 10 & 0 & $\Xi$ & $\stackrel{\infty}{\simeq}$ \\
\hline & \multirow{3}{*}{ 㐘 } & 吾 & $\infty$ & 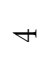 & or & ' & $\stackrel{\Delta}{\sim}$ & 0 & 으 & $\stackrel{\infty}{\sim}$ & 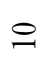 & 0 & $\stackrel{\infty}{=}$ \\
\hline & & 의 & $\sigma$ & 一 & ' & ' & $\Xi$ & 10 & or & $\infty$ & N & 으 & 20 \\
\hline & & $\infty$ & 0 & $\infty$ & ov & ' & $\stackrel{2}{=}$ & $\Xi$ & $\infty$ & 10 & $\infty$ & 0 & $\sqrt{0}$ \\
\hline & & & 플 & $\frac{\widetilde{\pi}}{.00}$ & 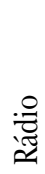 & 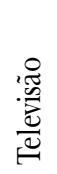 & 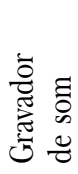 & 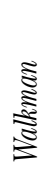 & 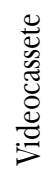 & 蛋 & 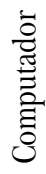 & & 定 \\
\hline
\end{tabular}


comunicação \& educação • Ano XI • Número 1 • jan/abr 2006

Tabela 2

Programação de rádio preferida

\begin{tabular}{|l|c|c|c|}
\cline { 2 - 4 } \multicolumn{1}{c|}{} & $8^{\underline{a}}$ & $3^{-}$ & TOTAL \\
\hline Musical & 26 & 21 & 47 \\
\hline Esporte & 3 & 2 & 5 \\
\hline Noticiário & 2 & 5 & 7 \\
\hline Entrevistas & 4 & 5 & 9 \\
\hline
\end{tabular}

Tabela 3

Preferência de estilo musical

\begin{tabular}{|l|c|c|c|}
\cline { 2 - 4 } \multicolumn{1}{c|}{} & $8^{\mathbf{a}}$ & $3^{\mathbf{o}}$ & TOTAL \\
\hline Todos & 8 & 10 & 18 \\
\hline Country & 1 & - & 1 \\
\hline Tecno/eletrônico & 2 & - & 2 \\
\hline Rock & 8 & 5 & 13 \\
\hline Forró & 5 & - & 5 \\
\hline Pagode/samba & 7 & 6 & 13 \\
\hline MPB & 2 & 2 & 4 \\
\hline Internacional/pop/rap/reggae & 8 & - & 8 \\
\hline Clássico & - & 1 & 1 \\
\hline
\end{tabular}

Tabela 4

Utiliza o computador para:

\begin{tabular}{|l|c|c|c|}
\cline { 2 - 4 } \multicolumn{1}{c|}{} & $8^{\underline{a}}$ & $3^{-}$ & TOTAL \\
\hline Pesquisa & 2 & 4 & 6 \\
\hline Lazer/jogo & 14 & 1 & 15 \\
\hline Estudo & 5 & 4 & 9 \\
\hline Trabalho & 7 & 8 & 15 \\
\hline Notícias & 3 & 1 & 4 \\
\hline Internet & 3 & 1 & 4 \\
\hline
\end{tabular}


Tabela 5

Favorável/desfavorável ao rádio em sala de aula

\begin{tabular}{|l|c|c|c|}
\cline { 2 - 4 } \multicolumn{1}{c|}{} & $8^{\mathbf{a}}$ & $3^{\circ}$ & TOTAL \\
\hline Favorável & 23 & 24 & 47 \\
\hline Desfavorável & 3 & - & 3 \\
\hline
\end{tabular}

Tabela 6

Argumentos favoráveis

\begin{tabular}{|l|c|c|c|}
\cline { 2 - 4 } \multicolumn{1}{c|}{} & $8^{\underline{\mathbf{a}}}$ & $3^{\circ}$ & TOTAL \\
\hline Acalma & 4 & 7 & 11 \\
\hline Motiva & 18 & 13 & 31 \\
\hline Não opinou & 4 & 4 & 8 \\
\hline
\end{tabular}

Tabela 7

Diferença da aula com rádio e sem rádio

\begin{tabular}{|l|c|c|c|c|c|c|}
\cline { 2 - 8 } \multicolumn{1}{c|}{} & \multicolumn{2}{c|}{$8^{\mathrm{a}}$} & \multicolumn{2}{c|}{$3^{\circ}$} & \multicolumn{2}{c|}{ TOTAL } \\
\cline { 2 - 8 } & com & sem & com & sem & com & sem \\
\hline Maior rapidez & 1 & - & - & - & 1 & - \\
\hline Maior rendimento & 2 & 1 & 4 & - & 6 & 1 \\
\hline Mais legal & 3 & - & 1 & 1 & 4 & - \\
\hline Melhor comportamento & 6 & - & 4 & - & 10 & \\
\hline Mais alegre & 6 & - & 8 & - & 14 & - \\
\hline Monótona & - & 4 & - & 4 & - & 8 \\
\hline Mais informação & - & - & 1 & - & 1 & - \\
\hline Nenhuma & 3 & - & 2 & - & 5 & - \\
\hline
\end{tabular}

Opiniões dos alunos ao assistirem aula, quando foi sintonizado o rádio pela primeira vez:

$\Rightarrow \quad$ Achei o máximo.

$\Rightarrow \quad$ Sinto-me como se estivesse em casa.

$\Rightarrow$ Relaxante, descontraída.

$\Rightarrow \quad$ Interessante e diferente pelo fato de nos deixar à vontade.

$=>$ Dinâmica, fantástica, toque mágico na sala de aula.

$\Rightarrow \quad$ De inicio, foi estranho, mas percebi que a classe ficou quieta e mais calma.

$\Rightarrow$ Tira o clima tenso.

=> Mais animada e proveitosa. 


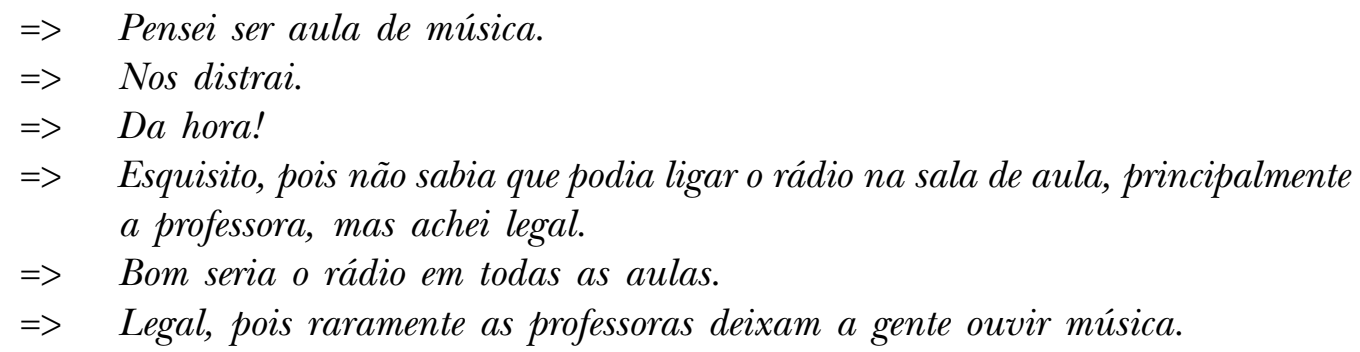

\section{ANÁLISE DOS DADOS}

Os dados oferecidos pelo questionário vêm ao encontro de tudo o que havíamos aprendido a respeito do uso dos meios de comunicação de massa em sala de aula. Os alunos demonstraram ser grandes consumidores dos meios de comunicação de massa - assistem à TV, por exemplo, até quatro horas e meia seguidas. Igual atenção dão ao rádio. Portanto, seu tempo é dividido entre a escola e o consumo midiático. Está claro que a escola não pode fechar os olhos a essa cultura na qual os jovens estão inseridos.

Nossa pesquisa revelou que os mais jovens - das $8^{\underline{a}}$ séries - são os que mais consomem produtos midiáticos diariamente. Esse hábito deve fazer parte do seu comportamento adolescente. É recomendável, portanto, que nessas séries do ensino fundamental se intensifique o uso dos meios de comunicação na escola, permitindo que aquilo que o aluno ouve e vê seja trabalhado pelo professor.

Dos meios mais utilizados, destacam-se a TV e o rádio, o que nos mostra a importância da linguagem audiovisual para nossos alunos. No entanto, a escola resiste em incorporar essa prática, fazendo do texto escrito sua única forma de comunicação e expressão válida e respeitada.

Dos meios de tecnologia mais atuais e sofisticados - vídeo, DVD, computador e internet - são os dois últimos os campeões de público, mostrando que a informática já é conhecida dos alunos de escolas públicas.

No que diz respeito aos meios impressos e às linguagens verbais escritas, as revistas são as campeãs de leitura, apontando para a necessidade de incorporálas à prática escolar.

Nossos alunos mostraram um consumo midiático mais coletivo do que individual. A TV é vista diariamente por 33 dos alunos pesquisados e o rádio, ouvido por 27. Já o walkman só é usado diariamente por $10 \%$ dos alunos.

Este é um dado muito importante para indicar o uso em sala de aula. Se é para se introduzir a música, que seja através de mídia de recepção coletiva.

No entanto, a escolha dos produtos midiáticos a serem introduzidos na prática educativa deve levar em conta o conhecimento e afinidade dos professores, pois o gosto dos alunos mostrou-se eclético.

Interessante notar a preferência por programas musicais, sendo que 47 dos alunos pesquisados disseram preferi-los ao esporte e noticiários. Das opções musicais, entretanto, manifestam-se, em sua maioria, pelo "todos", conforme tabela 3.

Com relação ao computador, este se apresenta igualmente como meio de lazer e de trabalho, o que confirma que os meios de comunicação de massa 
oferecem essa dupla possibilidade: trabalho e entretenimento não podem mais ser considerados atividades excludentes.

Perguntados a respeito de como vêem as atividades midiáticas na escola, 47 se mostraram favoráveis. Essa quase unanimidade nos motiva a continuar em nossa prática. Deles, 31 acham que as atividades com os meios de comunicação de massa são motivadoras e 11 afirmam que elas acalmam os estudantes.

Em função de qualquer uma dessas possibilidades, trata-se de uma razão muito importante para o rendimento escolar. Calmos e motivados, os alunos aprenderão mais, além de desenvolverem uma sociabilidade agradável e integradora.

Confirmando essa interpretação, a Tabela 7 apresenta-nos as opiniões precisas dos alunos, que nos levam a concluir que aprovam a inserção da música no cotidiano escolar. Chama-nos a atenção a opinião crítica e favorável em relação não só à inserção do rádio, como de outras mídias.

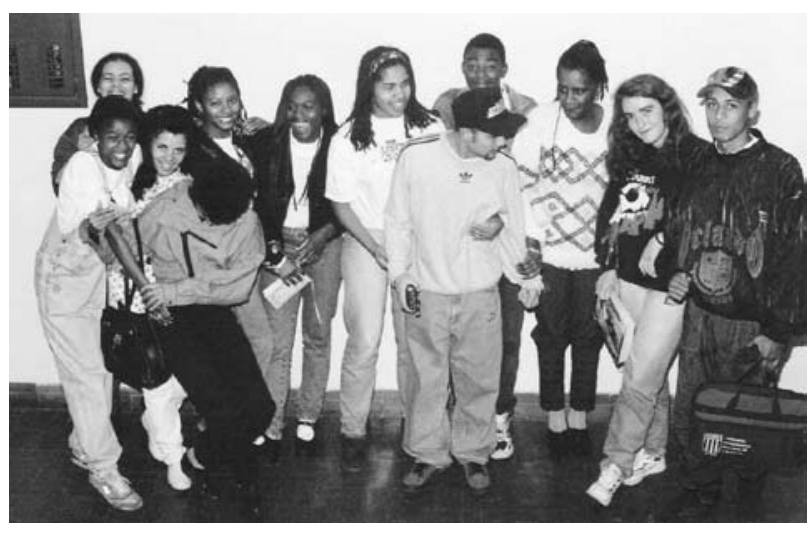

A profa. Ana com alunos da EE Godofredo Furtado (terceira, da direita para a esquerda).

Quanto ao uso do rádio na sala de aula:

- Dá mais rapidez para o aprendizado.

- É mais legal, mais alegre.

- Melhora o comportamento e os alunos agitados param de falar.

- A aula deixa de ser monótona.

- Melhora a atenção e participação.

\section{PLANEJANDO A EDUCOMUNICAÇÃO}

Os resultados da pesquisa apontaram diferentes direções. Mostraram que a inserção do rádio em sala de aula, ainda que realizada de forma experimental, tinha produzido bons resultados e os estudantes estavam conscientes disso. Mostraram também que a cultura midiática dos alunos é significativa e que as informações que dela recebem diariamente têm de ser levadas em conta pelos professores para que o conhecimento científico e filosófico que eles trazem possam se introduzir de forma mais harmoniosa e fácil na mente dos alunos. Em vez de colidir com as informações midiatizadas, os conteúdos da educação formal poderão juntar-se a elas e até modificá-las.

No entanto, para que isso ocorra de forma adequada, tornando-se apoio ao processo educativo e não mais um elemento de perturbação, é preciso planejamento, conforme aprendemos no curso de Gestão de Processos Comunicacionais. Assim, a partir da pesquisa, dediquei-me a algumas tarefas de planejamento educacional: 
comunicação \& educação • Ano XI • Número 1 • jan/abr 2006

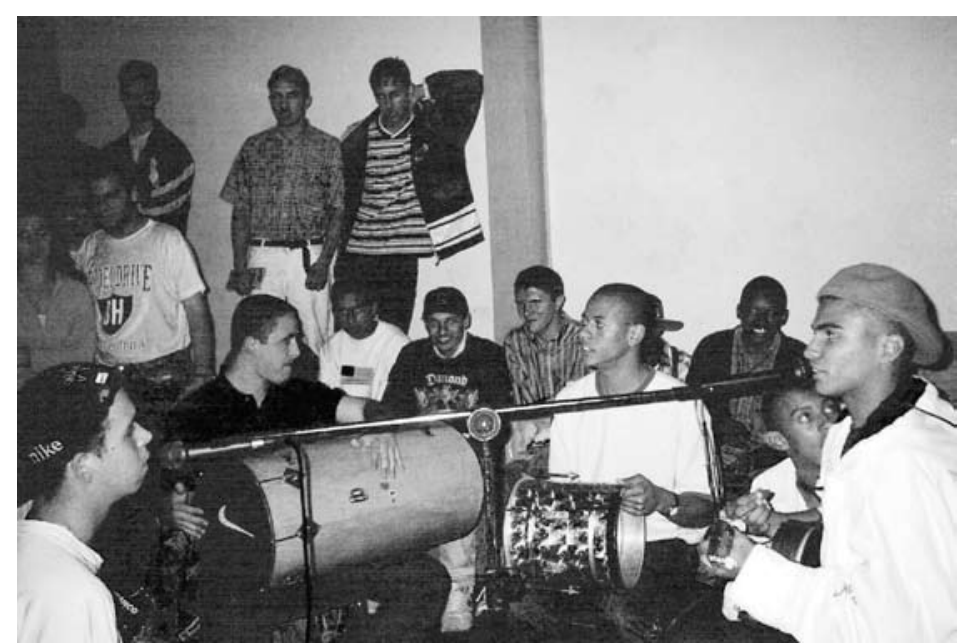

Educomunicação: a pesquisa pode avaliar a possibilidade de socialização dos resultados e reconfiguração do projeto para estendê-lo às demais turmas da escola.

1. Elaboração de um plano para divulgação da pesquisa junto aos professores da escola para que tomassem conhecimento das descobertas.

2. Formação de um grupo de trabalho com os professores mais abertos a experiências pedagógicas utilizando os meios de comunicação com vistas à elaboração de um projeto interdisciplinar.

3. Desenvolvimento detalhado desse projeto com o grupo de professores para dividir atribuições, de acordo com competências e afinidades pessoais.

4. Escolha de uma turma de alunos para testar a aplicação do projeto.

5. Apresentação do projeto aos alunos para sua colaboração (é importante que os alunos participem de projetos que os envolvem significativamente).

6. Avaliação do teste, modificações do projeto indicadas na avaliação, socialização dos resultados e planejamento para estender o projeto às demais turmas.

Resumo: Com base nos pressupostos da educomunicação, aprendidos no curso de Gestão da Comunicação da ECA/USP, a autora defende, através de pesquisa realizada na escola onde leciona, o uso dos meios de comunicação na prática educativa. Para desenvolver um projeto de intervenção com esse objetivo, realizou pesquisa de consumo midiático entre os alunos.

Palavras-chave: educomunicação, meios de comunicação, prática educativa, gestão da comunicação.
Abstract: Based on educommunication characteristics learnt at Communication Management course at ECA-USP, the author defends through research realised in the school she teaches the usage of mass communications on educational practice. In order to develop an intervention project with this aim, she realised a research on midiatic consumption among students.

Keywords: educommunication, mass communications, educational practice, communication management. 